\title{
Finding the Network Structure of Rwandan Interbank Market
}

\author{
Patrick Mugenzi ${ }^{1,2}$, Thomas Kigabo Rusuhuzwa ${ }^{1,2}$ \& Annie Uwimana ${ }^{1,2}$ \\ ${ }^{1}$ African Centre of Excellence in Data Science (ACE-DS), College of Business and Economics, University of \\ Rwanda, Rwanda \\ 2 National Bank of Rwanda, Rwanda \\ Correspondence: Patrick Mugenzi, African Center of Excellence in Data Science (ACE-DS), College of Business and \\ Economics, University of Rwanda, Rwanda. Tel: 250-785-907-912.
}

Received: December 21, 2020

Accepted: February 7, 2021

Online Published: March 14, 2021

doi:10.5430/ijfr.v12n3p435

URL: https://doi.org/10.5430/ijfr.v12n3p435

\begin{abstract}
The objective of this paper was to analyze the topology of interbank network in Rwanda for policy formulation. Our main result is that interbank market network in Rwanda is described by a core- periphery model with some level of completeness of interbank market in Rwanda. As policy implication, any risk from a bank is more easily shared within the interbank market network provided that there is nearly a complete network. This is an indication that the risk of instability of the financial system in Rwanda originating from interbank market is limited.
\end{abstract}

Keywords: interbank network, core periphery structure, network dynamics

\section{Introduction}

The National Bank of Rwanda (NBR) moved to a price based monetary policy in January 2019, using the interbank rate as operating target from monetary targeting framework used since 1997. In the new framework, the interbank market will play a crucial role in transmitting monetary policy impulses from central bank rate to interbank rate and to other money market rates; and to deposit and lending rates. To achieve this objective, the focus of NBR when intervening on money market will be to align interbank rates to the central bank rate (CBR) to anchor short-term interest rates. Thus, the interbank market represents the first link of liquidity trading in the economy and the transparent price setting mechanism, which improves savings mobilization and strengthen their market allocation. In the recent years, interbank market in Rwanda has facilitated the financing of short and medium term positions and the mitigation of liquidity risk by commercial banks. It has contributed to smoothening financial intermediation and boosting the lending to the economy by helping banks not to hold more liquidity for precautionary purpose as the market facilitates payment processing, and help banks meeting legal reserve requirements.

The interbank market in Rwanda has become very active and it involves all 15 commercial banks in the country. The total transactions in the interbank market amounted to FRW 613 billion in the period starting from 2013-2015 and to FRW 3255 billion in the period 2016-2019, which is an increase of 531 percentages. In 2018 and 2019, the total transactions in interbank market increased to 20.3 percent and 45.1 percent respectively from an average of 14.9 percent in the period 2015-2017.

However, the recent development of interbank market in Rwanda and its role for commercial banks to manage their liquidity and protect themselves against idiosyncratic liquidity shocks creates risk of contagion in the case of large shocks to one or few banks. The existing literature on network structure in interbank markets show that the magnitude of impact to the entire market from a shock to single or few banks is different whether the network is complete or clustered (Allan and Gale, 2000, Freixas et al., 2000). In the case of a complete network, i.e. network where all banks (nodes) are connected to all other banks, a shock to a single bank can not only lead to instability of the system as the impact of the shock but it can also easily be shared between all banks. However, if the network is much connected, spillover of some of the banks can become substantial due to their importance in the network. The recent global financial turmoil and its effects on interbank markets has increased the need of better understanding of bank interconnectedness and has helped to identify key players in the financial network because risk externalities of bank behavior call for a macro prudential approach, which goes beyond the traditional micro-prudential supervision (see Crockett, 2000; Iñaki Aldasoro and Iván Alves, 2017). Furthermore, the current economic impact of COVI-19 pointed to the need of identifying key players in the banking network. Financial sector is expected to play an 
important role to mitigate the impacts of COVID-19 on the real economy by providing bridge financing and restructuring of loans for their clients. This poses serious threat due to credit and liquidity risks due to different factors including the slowdown in economies.

Therefore, for NBR which is not only responsible for monetary policy management but also the regulator of the banking sector in Rwanda, a good grasp of the structure of the interbank market is crucial for a better understanding of the fragility of the banking sector to shocks. On the one hand, to better anticipate policy responses in the new forward looking monetary policy, it is important for NBR to understand market forces that influence the supply and demand of liquidity, which are determinants of the structure of interbank market network. Hence, understanding the knowledge of the topology of interbank market will help to identify possible contagion in the case of shock in a bank or number of banks and take necessary measures to ensure the stability of the system given the strong relationship between structures and resilience, robustness, contagion and efficiency of interbank markets (see Memmel and Sachs, 2013; A.V. Leonidov, at al., 2016).

The objective of this paper, which is the first to our best knowledge, is to analyze the topology of interbank network in Rwanda. More precisely, we assess if the interbank market in Rwanda can be described by a core periphery model which is commonly used in different research to analyze structure of interbank markets (Craig and Von Peter, 2014; in't Veld and van Lelyveld., 2014; Daniel Fricke and Thomas Lux, 2014 and Teruyoshi K and Taro T, 2018). Furthermore, in the case a core periphery model has been identified, we analyze if core banks in Rwanda are different in terms of risk measures because core banks are systemically more important in passing through shocks. This helps to make the results of this research relevant for financial stability assessment.

The rest of the paper is structured as follow: in the section 2 we present related literature, next we discuss the methodology used to determine the structure of interbank market in Rwanda in section 3. In addition, analysis of empirical results are presented in section 4, and finally with a conclusion in section 5 .

\section{Literature Review}

Graph or network theory was developed many years ago and is applied in different areas. Erdos and Renyi (1959) was the first to shed light on insightful notion around network theory. Their work underlies in random model with homogenous share in degree distributions, which later deemed not fit in financial networks.

In addition, another strand of literatures later revealed another structure "scale free" which follows stochastic process in link formation. In a pioneer paper, Barabasi and Albert (1999) proposed a scale free model, which is not subject to the change in size of the network and follows a power law distribution that in turn, allow banks with many connections to attract more linkages over time. Boss et al. (2004), using Austrian interbank data, are the first to provide an empirical analysis of the structural features of a real-world interbank network using network theory and they found a scale free network. Many other existing interbank networks have been described to resemble scale-free networks, such as the European interbank market for large banks (Alves et al., 2013), the Italian interbank market (De Masi et al., 2006), the Colombian payment and settlement systems (Leon and Berndsen, 2014) as well as the US Fedwire system (Soramaki et al., 2007), the Mexican interbank market (Martínez-Jaramillo et al. 2014).

In contrast, numerous findings assert that interbank network follows deterministic model such as core periphery structure which stipulates that core banks are much connected and intermediate between periphery banks while the later are not connected with each other. The structure of this kind was earlier introduced in social science by Borgatt and Everett (1999). Using German dataset, Craig and von Peter (2014) was the first in expending core periphery structure in interbank market. A good number of researches discovered that interbank markets are well fitted by a core-periphery structure: the UK market (Langfield et al., 2014) and the Dutch market (in't Veld and van Lelyveld, 2014), as well as the e-MID trading platform (Iori et al., 2008; Fricke and Lux, 2014), the US federal funds market (Bech and Atalay, 2010), (Hommes et Al., 2013; Castiglionesi and Navarro, 2011; Thomas Lux, 2014) and many others were found to exhibit this structure.

In the aftermath of 2008/2009 financial crises, a number of researches around the network structure and its effect in propagating contagion risk have been constantly increasing. However, the research of this kind was even there before the crisis occurred, and it was firstly explored by Allen and Galle (2000). They asserted that network topology stands as key feature in understanding financial contagion. Mastromatteo et al. (2012) shows that understanding network topology is crucial to designing proper stress tests and to developing methods to accurately estimate risk.

There is a long lasting debate on how and at what extent distinct network structures matter in prompting or curb systemic risk in interbank market culminating to their roles in financial stability. Various bodies of work assert that a scale free network is more robust than a highly interconnected network (Battiston et al. 2012); This view takes a 
position which differs from that of (Allen and Gale, 2000; Freixas et al., 2000; Chinazzi et al., 2013) who suggested that a highly connected interbank network enhances the resilience of the system to the insolvency of an individual bank. Chinazzi et al. (2013) argue that high-interconnected networks may allow adverse shocks to wear off quicker.

Albert et al. (2000) point out, scale-free networks are relatively robust to the random breakdown of nodes. However, the system is very vulnerable to the risk of the specific removal of hubs, which can even lead to its collapse (Haldane, 2009), robust-yet-fragile concept. This fact was also evidenced by Markose et al. (2010), they argued that a coreperiphery framework might be more robust in 'normal' times, but more fragile under exceptional circumstances when key nodes are under stress or withdraw from the market,

Nier et al. 2007 balances the debate and argues that the effect of the degree of connectivity is non-monotonic, that is, initially a small increase in connectivity increases the contagion effect; but after a certain threshold value, connectivity improves the ability of a banking system to absorb shocks. In addition, Acemoglu et al. (2015) looks at the magnitude of shock and interconnectedness; and shows that for small shocks denser networks are resilient; however, if the level of these shocks goes beyond a certain threshold, more connected networks then exacerbate the contagion risk in the network, leading to robust yet fragile financial system.

The prevalent fact argued by Roukny et al. (2013) is that network topology matters when markets are illiquid and no interbank network structure is superior to others in terms of mitigating systemic risk. In fact, they evidenced that network topology does not determine the stability of the system alone, and this reality is consistent with the previous findings which asserts that the stability of financial system depends on the magnitude of the shocks.

To sum up, the network theory has caught attention in more than a half century ago and more recently understanding the structure of a network is important for tracking its resilience, hence policymakers should be interested in the actual topology of the interbank network. Our paper is inclined to the work of Craig and von Peter (2014) in finding the network structure of Rwandan Interbank Market and more specifically tests the emergence of core periphery structure in this market.

\section{Methodology}

To analyze the structure of interbank market network in Rwanda we used daily amount of borrowings by 15 commercial banks. Data used cover the period from first quarter of the year 2015 to the last quarter of 2019 and are from the National Bank of Rwanda. The most common mathematical representation of a network, which we use in this research, is the adjacency matrix. Let $\mathrm{n}$ represent the number of vertexes (nodes) or banks participating in the interbank market. The adjacency matrix $\mathrm{M}$ is a square matrix of dimensions $n \times n$ with elements

$m_{i j}$ equals to 1 when there exist a connection between banks $i$ and $j$; and zero otherwise.

To take into consideration the importance of each bank in interbank market transitions, we use a weighted network, with $Z_{i j}$ being the weight associated to a connection of $i$ to $j$ in the network and defined as follow:

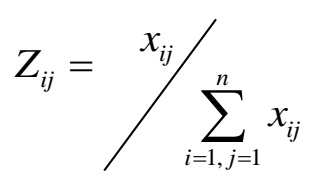

$x_{i j}$ is the amount of money borrowed from bank $i$ by the bank $j$ and $\sum_{i=1, j=1}^{n} x_{i j}$ represents the total amount

borrowed in the banking system.

To measure the level of connection of each bank in the network we calculate the degree $\left(k_{i}\right)$ of a bank, which is the number of banks to which it lends (out degree, $k^{\text {out }}$ ) or from which it borrows (in degree, $k^{\text {in }}$ ) as well the weighted degree S. This is important in the interbank market network analysis because the probability of forming links by a bank increases with its degree. In other words, a bank with large number of interactions has high probability of attracting more link over the time (Barabasi and Albert, 1999).

$$
k_{i}^{\text {in }}=\sum_{j=1}^{n} A_{j i} ; k_{i}^{\text {out }}=\sum_{j=1}^{n} A_{i j} ; S_{i}^{\text {in }}=\sum_{j=1}^{n} Z_{j i} \text { and } S_{i}^{\text {out }}=\sum_{j=1}^{n} Z_{i j}
$$


To understand the characteristics of our network, we used the following power law distribution $p_{k}=k^{-\gamma}$, where $p_{k}$ stands for the probability that a node has degree $\mathrm{k}$ and $\gamma$ is the power law exponent. In such networks, there are a few nodes with extremely high degree while other nodes have only a few links.

Another simplest metric for approximating the connective pattern is the density (d), which measures the cohesion of the network. The density of a graph with no self-edges is the ratio of the number of actual edges $(\mathrm{m})$ to the maximum possible number of edges. Since a bank does not lend to itself, the maximum number of interconnections (edges) is $n(n-1)$, which represents a complete market. We define the degree of completeness of the market or network density by

$$
d=\frac{m}{n(n-1)}
$$

By construction, density is restricted to $0<d \leq 1$ range. Formally, Newman (2010) states that a sufficiently large network for which the density (d) tends to a constant as $n$ tends to infinity is said to be dense. In contrast, if the density tends to zero as $n$ tends to infinity the network is said to be sparse. To better understand the structure of interbank market network in Rwanda, we test the concept of an interbank core periphery network following Craig and von Peter (2014). The starting point will be the use of k-core decomposition algorithm developed by Csardi G, Nepusz $\mathrm{T}$ (2006). The k-core of graph is a maximal subgraph in which each vertex has at least degree $\mathrm{k}$. The coreness of a vertex is $\mathrm{k}$ if it belongs to the $\mathrm{k}$-core but not to the $(\mathrm{k}+1)$-core. This stands as starting point in determining core banks in the network. To evaluate the fit of our models to network data, we identify the optimal core model, which is the one producing the smallest number of errors among all possible cores.

To assess how banks have been extending their connections in the network, we use centrality measure such as average clustering coefficient and average path length. This is important because, in a network where all nodes are connected (or closed to a complete network), a shock to a bank could not lead to instability of the system as pointed out in the introduction. The clustering coefficient $(\mathrm{C})$ measures the average probability that two neighbors of a vertex are themselves neighbors. The coefficient hence measures the frequency with which loops of length three (i.e. triangles) appear in the network (Boss at.al, 2004).In a well-established and big interbank market, $\mathrm{C}$ is expected to be small. Though banks may be interested to diversify partners in the network, keeping a link may be costly. However, in markets, which are in the process of development, $\mathrm{C}$ can have high values.

$$
C=\frac{3 n t}{n c}
$$

$n t$ is the number of triangles on the graph while $n c$ is the number of connected triples of vertices.

Average path length is defined as the average number of steps along the shortest paths for all possible pairs of network nodes. It is calculated as sum of all shortest paths between all vertices divided by the number of all possible paths.

$$
l_{G}=\frac{1}{n(n-1)} \sum_{i \neq j} d\left(v_{i}, v_{j}\right)
$$

$d\left(v_{i}, v_{j}\right)$ is the length of shortest path which exists between two vertices.

Finally, to scrutinize the dependence of core periphery structure on banks' asset size we use Pearson Chi-square test classifying banks as large or small banks with respect to the threshold of 100 Billion FRW.

\section{Analysis of Results}

The analysis of interbank market activities in Rwanda shows that the market has been very active since 2015, paving the way for the adoption by NBR of price based monetary policy in January 2019. The annual volume of transactions increased from FRW 242 billion in 2015 to 1,662 billion in 2019 and in recent period almost all banks, including small banks transact on interbank market. This is due to the awareness of NBR about the importance of interbank market and the improvement in regulatory framework and infrastructures key for the well-functioning of money market in general. Most of the banks have been active both in terms of borrowing (incoming links) and lending (outgoing links). This being said, the maximum incoming links reached to 9 in 2019 from 7 links in 2015, while the maximum outgoing links extended up to 11 in 2019 from 6 in 2015 (see Table 3).

Given the heterogeneity in banks in-degree (incoming links) and out-degree (outgoing links), we investigated the best fitness of the in-degree and out-degree distribution of Rwandan interbank in the last five years. The distribution 
of the number of links by bank is an important feature of different network models (in't Veld and van Lelyveld, 2014; Boss et.al, 2004). Figure 1 shows that both in-degree and out-degree follow a power law distribution, the proportion of banks with degree higher than $\mathrm{k}$ reducing when $\mathrm{k}$ increases. It also shows the existence of some banks with high degree, reaching up to between 67 and 73 percent of all banks in some years, indication of the existence of core banks. This is supported by the jump in the out degree for some periods making difference between core and periphery banks.
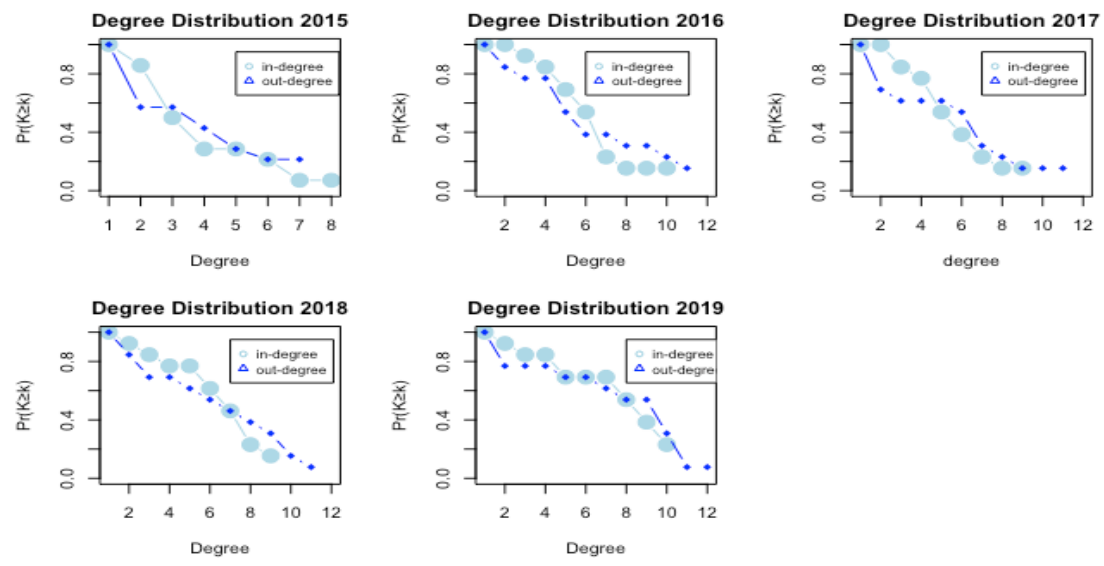

Figure 1. Cumulative degree distribution of interbank market network

To further investigate the fit of Core-Periphery (CP) model to the interbank network data in Rwanda, we apply k-core decomposition algorithm developed by Csardi G, Nepusz T (2006) using data for the year 2015.The graph in appendix A reveals a clustering of banks, with 7 banks out of 15 considered as core, with 4 degree $(\mathrm{k}=4)$ each. Applying the same procedure in the period 2015-2019, the analysis shows that five out the seven core banks in 2015 remained consistently core in the rest of years. In addition, the number of core banks increased to 9, except in 2018 where they reduced to 6 (Appendix B). A core group composed with 8 banks $(3,4,5,8,10,11,12,13$ ), which persistently emerged as more connected since 2016 stand out as large banks in the network considering our threshold total assets exceeding 100billion Rwf.

Another important point we analyzed in this paper is the stability of the network. As indicated in the transition matrix which shows the change of nodes in being core, periphery or inactive in the interbank market (Exit), 91.7\% of the core banks remained in the core for the next period confirming the stability of the number of core banks (table 1). In addition, the density of the network has been increasing over time and the number of degrees increased which shows how core banks have been expending their connection in the network (Table 2).

Furthermore, error score significantly reduced in the recent period to 0.15 and 0.26 in 2018 and 2019 from $0.78 ; 0.59$ and 0.53 in 2015, 2016 and 2017 respectively, indication of how the fitness of CP model to interbank market in Rwanda improved in recent years (Appendix C).

Table 1. Transition matrix of nodes in 3 different states (core, periphery and inactive)

\begin{tabular}{llll}
\hline & Core & Periphery & Inactive \\
\hline Core & $91.7 \%$ & $8.3 \%$ & $0 \%$ \\
Periphery & $17.8 \%$ & $66.07 \%$ & $16.08 \%$ \\
Inactive & $0 \%$ & $25 \%$ & $75 \%$ \\
\hline
\end{tabular}

As indicated in the Table 3, the average path length had a downward trend while clustering coefficient had an upward trend during the past five years. These findings show that in recent years, number of interbank connections has been increasing as the market developed making it easy to absorb a shock from one or small number of banks as 
pointed out. The average clustering coefficient was more than double from 0.222 in 2015 to 0.584 in 2019 but has become stable in the last two years. However, one can expect the coefficient to become small with the level of development of the market, reducing the capacity of the system to absorb a shock from a bank in the network. For example, as strong relationship will be established, two small banks connected to a big bank may reach a level of not needing link among themselves.

Table 2. Summary statistics of dynamic interbank in Rwanda

\begin{tabular}{llllll}
\hline Coefficients & 2015 & 2016 & 2017 & 2018 & 2019 \\
\hline Density & 0.176 & 0.391 & 0.339 & 0.3974 & 0.4871 \\
Av.in deg & 2 & 4 & 4 & 5 & 6 \\
Max.in deg & 7 & 8 & 8 & 8 & 9 \\
Max.outdeg & 6 & 10 & 10 & 10 & 11 \\
Med. out deg & 2 & 5 & 5 & 5 & 8 \\
\hline K-core & 4 & 7 & 8 & 8 & 9 \\
\hline Av.Path Length & 2.048 & 1.636 & 1.648 & 1.509 & 1.342 \\
\hline Av.Clustering Coeff. & 0.222 & 0.479 & 0.449 & 0.567 & 0.584 \\
\hline Edges & 32 & 61 & 53 & 62 & 76 \\
\hline
\end{tabular}

Finally, we assessed the characteristics of core banks to understand at what extent findings of this study are relevant to banking sector stability assessment by NBR. The existing literature shows that core banks tend to be the larger banks, lower buffer defined as the Tier 1 capital over total assets, mainly due to their expertise in liquidity management and high level of activities compared to small and medium banks and higher management quality defined as cost to income ratio (Craig and Von Peter 2010; in't Veld and van Lelyveld, 2014). Being large and interconnected makes a bank more systemically important bank. The Figure 2 shows that on average, core banks have a big size, measured by total assets, compared to periphery banks. Using Pearson Chi-square test and classifying banks as large or small banks with respect to the threshold of 100 Billion Rwf, we conclude that there is a significant correlation between banks 'size and core periphery structure (Chi-square statistic:6.35, P-Value:0.018) i.e core banks tend to be larger and small banks to be periphery in interbank network in Rwanda. Though the core group has higher average size than periphery, we observed that there is a sub group of core banks with medium size comparable to some banks in periphery. Two banks in periphery have higher size compared to a number of core banks in the period under review. In addition, core banks have lower buffer defined as the Tier 1 capital over total assets averaging 19.5 percent compared to 43.7 percent in the period under review. Furthermore, in line with other research on interbank network, core banks have higher return on assets and lower cost to income, a sign of higher management quality (look at Figure 3 and appendix D respectively).

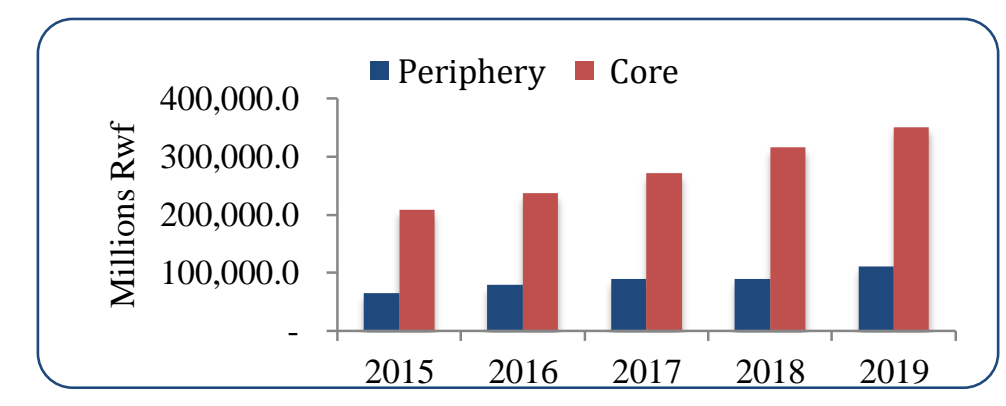

Figure 2. Average total assets 


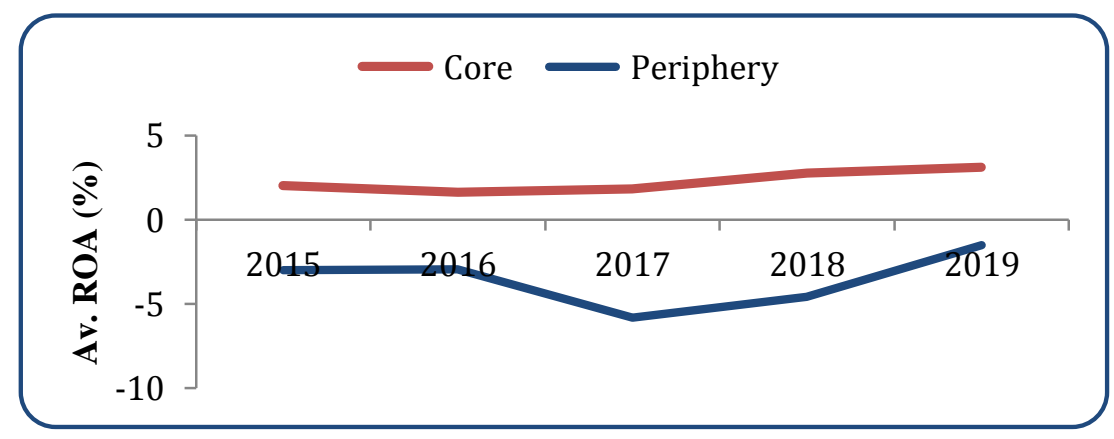

Figure 3. Return on assets

\section{Conclusion}

The National Bank of Rwanda (NBR) moved to a price based monetary policy in January 2019, using the interbank rate as operating target. The bank will focus on aligning the interbank rates to the central bank rate (CBR) through its interventions on money market to anchor short-term interest rates. In the new monetary policy framework, interbank market is expected to play an important role in transmitting the monetary policy impulses. However, interbank market can be a source of risk contagion among banks and the magnitude of impact from a shock to single or few banks depends on the structure of the interbank network. The objective of this paper was to analyze the topology of interbank network in Rwanda for policy formulation.

Our main result is that interbank market network in Rwanda is described by a core- periphery model with 8 banks out of 15 remained core in 2016, 2017, and 2019, except in 2018 when two banks shifted from core to periphery. This is confirmed by higher probability (91.7 percent) for a bank to remain core in next period. In addition, our findings show an increasing trend in both network density and degree (in and out degree) and coreness degree indicating some level of completeness of interbank market in Rwanda. This finding is important because high banks interconnectedness allows for the effective transmission of monetary policy impulses, which makes financial institutions more capable of absorbing idiosyncratic shocks, and ultimately it is essential for the overall functioning of the financial system. This is an indication that the risk of instability of the financial system in Rwanda originating from interbank market is limited. However, one can expect the level of interconnectedness reducing as the market is developing making the network less complete and vulnerable to shock from one or a number of banks. Thus, it will be important for the National Bank of Rwanda to regularly have an - updated understanding about the topology of the interbank market in Rwanda.

In this paper, we have focused on the structure of the network by using deterministic model particularly known as core periphery structure and we have analyzed if core banks in Rwanda are different in terms of risk measures. The analysis carried out, however has solely dealt with interbank trading data as the direct contagion channel. Thus, further research is needed in exploring other channels of contagion risk such as banks 'similarity in loan portfolios. In addition, the present paper opens up avenues for systemic risk assessments given the failure of individual banks (core banks or periphery banks) to deliver further guidelines for supervisory authorities during financial turmoil.

\section{Acknowledgements}

The views expressed in this paper do not necessarily reflect those of the institutions the authors are affiliated with. We thank the National Bank of Rwanda for granting access to dataset used in this research. We are grateful for the financial support provided by African Centre of Excellence in Data Science (ACE-DS), University of Rwanda. We would also like to express our sincere thanks, to Jean Fiacre Haliyamutu for proofreading the final version of this research.

\section{References}

Acemoglu, D., Ozdaglar, A., \& Tahbaz-Salehi, A. (2015). Systemic risk and stability in financial networks. Am. Econ. Rev., 105, 564-608. https://doi.org/10.1257/aer.20130456

Albert, R., Jeong, H., \& Barabasi, A.-L. (2000). Error and attack tolerance of complex networks. Nature, 406(6794), 378-382. https://doi.org/10.1038/35019019

Allen, F., \& Gale, D. (2000). Financial contagion. J. Polit. Econ., 108, 1-33. https://doi.org/10.1086/262109 
Alves, I., Ferrari, S., Franchini, P., Heam, J., Jurca, P., Langeld, S., ... Vuillemey, G. (2013). The structure and resilience of the European interbank market. ESRB Occasional Papers, 3.

Barabási, A.-L., \& Albert, R. (1999). Emergence of Scaling in Random Networks. Science, 286, 509-512. https://doi.org/10.1126/science.286.5439.509

Battiston, S., DelliGatti, D., Gallegati, M., Greenwald, B. C., \& Stiglitz, J. E. (2012). Liaisons dangereuses: increasing connectivity, risk sharing, and systemic risk. J Econ Dyn Control, 36(8), 1121-1141. https://doi.org/10.1016/j.jedc.2012.04.001

Bech, M. L., \& Atalay, E. (2010). The topology of the federal funds market. Phys A, 389(22), 5223-5246. https://doi.org/10.1016/j.physa.2010.05.058

Borgatti, S. P., \& Everett, M. G. (1999). Models of core/periphery structures. Social Networks, 21, 375-395. https://doi.org/10.1016/S0378-8733(99)00019-2

Boss, M., Elsinger, H., Summer, M., \& Thurner, S. (2004). The network topology of the interbank market. Quantitative Finance, 4(6), 677-684. https://doi.org/10.1080/14697680400020325

Castiglionesi and Navarro. (2011). Fragile Financial Networks. Mimeo. Tilburg University.

Chinazzi, M., Fagiolo, G., Reyes, J. A., \& Schiavo, S. (2013). Post-mortem examination of the international financial network. J. Econ. Dyn. Control, 37, 1692-1713. https://doi.org/10.1016/j.jedc.2013.01.010

Craig, B. R., \& Von Peter, G. (2014). Interbank tiering and money center banks. Journal of Financial Intermediation, 23(3), 322-347. https://doi.org/10.1016/j.jfi.2014.02.003

Crockett, A. D. (2000). Marrying the micro- and macro-prudential dimensions of financial stability. In A. D. Crockett (Ed.), General Manager of the Bank for International Settlements and Chairman of the Financial Stability Forum, before the Eleventh International Conference of Banking Supervisors, held in Basel, 20-21 September 2000.

De Masi, G., Iori, G., \& Caldarelli, G. (2006). Fitness model for the Italian interbank money market. Phys. Rev. E, 74, 066112. https://doi.org/10.1103/PhysRevE.74.066112

Erdõs, P., \& Rényi, A. (1959). On random graphs. Publicationes Mathematicae, 6, 290-297.

Freixas, X., Parigi, B. M., \& Rochet, J.-C. (2000). Systemic risk, interbank relations, and liquidity provision by the central bank. Journal of Money, Credit and Banking, 32(3), 611-638. https://doi.org/10.2307/2601198

Fricke, D., \& Lux, T. (2014). Core-periphery structure in the overnight money market: evidence from the e-mid trading platform. Comput Econ. https://doi.org/10.1007/s10614-014-9427-x

Gabor, C., \& Tamas, N. (2006). The igraph software package for complex network research. Inter Journal. Complex Systems.

Haldane, A. G. (2009). Rethinking the financial network. Speech delivered at the Financial Student Association in Amsterdam (April).

Hommes, C., Van der Leij, M., \& In 't Veld, D. (2013). The Formation of a Core-Periphery Network in Interbank Markets. Working paper, University of Amsterdam.

In 't Veld, D., \& Van Lelyveld, I. (2014). Finding the core: network structure in interbank markets. J. Bank. Financ, 49, 27-40. https://doi.org/10.1016/j.jbankfin.2014.08.006

Iñaki Aldasoro, I. A. (2017). Multiplex interbank networks and systemic importance-An application to European data. BIS Working Papers No 603.

Iori, G., Masi, G. D., Precup, O. V., Gabbi, G., \& Caldarelli, G. (2008). A network analysis of the Italian overnight money market. J. Econ. Dynam. Control, 32. https://doi.org/10.1016/j.jedc.2007.01.032

Kobayashi, T., \& Takaguchi, T. (2018). Identifying relationship lending in the interbank market: A network approach. Journal of Banking \& Finance, 97. https://doi.org/10.1016/j.jbankfin.2018.09.018

Langfield, S., Liu, Z. J., \& Tomohiro, O. (2014). Mapping the UK interbank system. Journal of Banking \& Finance, 45(2014), 288-303. https://doi.org/10.1016/j.jbankfin.2014.03.031

Leon, C., \& Berndsen, R. J. (2014). Rethinking financial stability: Challenges arising from financial networks' modular scale-free architecture. Journal of Financial Stability, 15(0), 241-256. https://doi.org/10.1016/j.jfs.2014.10.006 
Leonidov, A. V., \& Rumyantsev, E. L. (2016). Default contagion risks in Russian interbank market. PhysicaA, 451(2016), 36-48. https://doi.org/10.1016/j.physa.2015.12.130

Markose, S., Giansante, S., \& Shaghaghi, A. R. (2012). Too interconnected to fail' financial network of US CDS market: Topologicalfragility and systemic risk. Journal of Economic Behavior and Organization, 83(3), 627-646. https://doi.org/10.1016/j.jebo.2012.05.016

Martínez-Jaramillo, S., Alexandrova-Kabadjova, B., Bravo-Benítez, B., \& Solórzano-Margain, J. P. (2014). An empirical study of the Mexican Banking System's network and its implications for systemic risk. Journal of Economic Dynamics and Control, 40, 242-265. https://doi.org/10.1016/j.jedc.2014.01.009

Mastromatteo, I., Zarinelli, E., \& Marsili, M. (2012). Reconstruction of financial networks for robust estimation of systemic risk. J. Stat. Mech: Theory Exp., P03011. https://doi.org/10.1088/1742-5468/2012/03/P03011

Memmel, C., \& Sachs, A. (2013). Contagion in the interbank market and its determinants. Journal of Financial Stability, 9(2013), 46-54. https://doi.org/10.1016/j.jfs.2013.01.001

Newman, M. E. J. (2010). Networks: An Introduction. Oxford University Press.

Nier, E., Yang, J., Yorulmazer, T., \& Alentorn, A. (2007). Network models and financial stability. J. Econ. Dyn. Control, 31, 2033-2060. https://doi.org/10.1016/j.jedc.2007.01.014

Roukny, T., Bersini, H., Pirotte, H., Caldarelli, G., \& Battiston, S. (2013). Default cascades in complex networks: topology and systemic risk. Sci.Rep., 3, 2759. https://doi.org/10.1038/srep02759

Soramäki, K., Bech, M., Arnold, J., Glass, R., \& Beyeler, W. (2007). The topology of interbank payment flows. Physica A, 379(1). https://doi.org/10.1016/j.physa.2006.11.093

Thomas, L. (2014). Emergence of a core-periphery structure in a simple dynamic model of the interbank market. Journal of Economic Dynamics \& Control, 52(2015), A11-A27. https://doi.org/10.1016/j.jedc.2014.09.038 


\section{Appendix A}

Interbank Network Using k-Core Decomposition (k=4)

Interbank network 2015

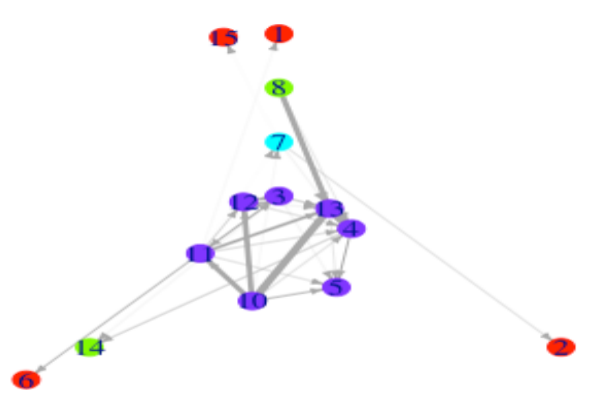

\section{Appendix B}

Transition of Core and Periphery Nodes Over Time, 2015Q1-2019Q4

\begin{tabular}{|c|c|c|c|c|}
\hline 2015 & 2016 & 2017 & 2018 & 2019 \\
\hline \multirow[t]{2}{*}{ Node (ID) Core } & Core & Core & Core & Core \\
\hline & 1 & 1 & & 3 \\
\hline 3 & 3 & 3 & 3 & 4 \\
\hline 4 & 4 & 4 & 4 & 5 \\
\hline \multirow[t]{2}{*}{5} & 5 & 5 & & 7 \\
\hline & 8 & 8 & 8 & 8 \\
\hline 10 & 10 & 10 & & 10 \\
\hline 11 & 11 & 11 & 11 & 11 \\
\hline 12 & 12 & 12 & 12 & 12 \\
\hline 13 & 13 & 13 & 13 & 13 \\
\hline Periphery & Periphery & Periphery & Periphery & Periphery \\
\hline 1 & & & 1 & 1 \\
\hline 2 & & 2 & 2 & 2 \\
\hline 6 & 6 & & 5 & \\
\hline 7 & 7 & 7 & 7 & \\
\hline 8 & & 9 & 9 & 9 \\
\hline 14 & 14 & 14 & 10 & 14 \\
\hline 15 & 15 & & 14 & \\
\hline Total Nodes 14 & 13 & 13 & 13 & 13 \\
\hline
\end{tabular}




\section{Appendix C}

Core Periphery Model Fitness of Rwanda Interbank Market Network for Five-Year Period (2015-2019)

\begin{tabular}{llllll}
\hline & 2015 & 2016 & 2017 & 2018 & 2019 \\
\hline Error Condition1 & 21 & 30 & 26 & 4 & 19 \\
\hline Error condition2 & 2 & 1 & 0 & 5 & 2 \\
\hline Error condition3 & 2 & 5 & 2 & 0 & 2 \\
\hline Total Errors (E) & 25 & 36 & 28 & 9 & 20 \\
\hline L & 32 & 61 & 53 & 62 & 76 \\
\hline Error score:(E/L) & 0.78 & 0.59 & 0.53 & 0.15 & 0.26 \\
\hline
\end{tabular}

\section{Appendix D}

Management Quality or Cost to Income

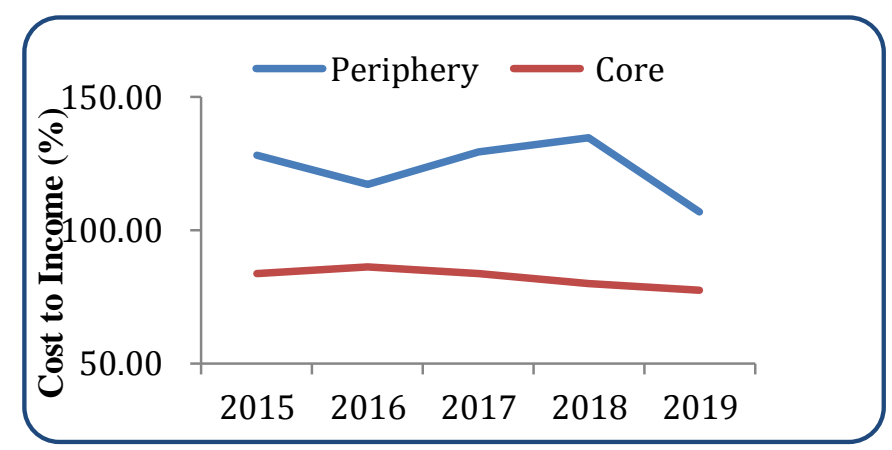

\section{Appendix E}

\section{Interbank Market Development}

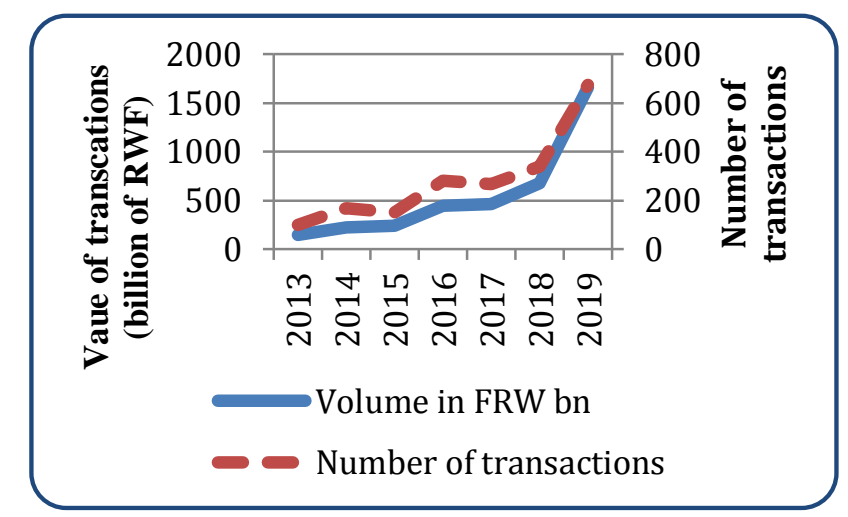

\section{Copyrights}

Copyright for this article is retained by the author(s), with first publication rights granted to the journal.

This is an open-access article distributed under the terms and conditions of the Creative Commons Attribution license (http://creativecommons.org/licenses/by/4.0/). 